\title{
Fiberoptic Bronchoscopic Removal of Dental Crown Dropped in Bronchus During Dental Treatment
}

\author{
Takanori Ayabe*1, Masaki Tomita ${ }^{1}$, Ryo Maeda ${ }^{1}$, Kosuke Mori ${ }^{1}$ and Kunihide Nakamura ${ }^{2}$ \\ ${ }^{1}$ Division of Thoracic and Breast Surgery, Department of Surgery, Japan \\ ${ }^{2}$ Division of Cardiovascular Surgery, Faculty of Medicine, Japan
}

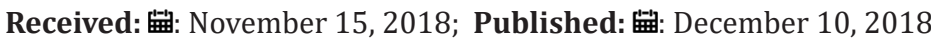

*Corresponding author: Takanori Ayabe, Division of Thoracic and Breast Surgery, Department of Surgery, Japan

\begin{abstract}
Background: Aspiration and ingestion of foreign bodies are rare and risky complication during dental procedure. For a metal paradium with a very smooth surface stuck in the lower endobronchus, it was difficult to grasp and remove. Fortunately, we could remove it by a minimally invasive technique by flexible bronchoscopy.

Case Report: A 57-year old male diagnosed with schizophrenia had been treated for tooth decay. During covering a dental crown, the palladium was dropped in the oral space. As he had a continuous cough, the dental crown was suspected to be aspirated, thus he was transferred to a hospital. Chest radiography showed an artifact in the left lower lung field, which showed a foreign metal body in the left basal segmental bronchus of B9 of the lung. An endobronchial foreign body was diagnosed, and endoscopic removal was needed as the first step before surgical removal. Under airway anesthesia, a flexible bronchoscopy was guided to the stuck dental crown in the B9 bronchus, which was successfully removed by grasping with alligator forceps.
\end{abstract}

Conclusion: The removal of a foreign body by a flexible fiberoptic bronchoscopy can be performed in minimally invasive and safety modality as a first choice in order to avoid surgical removal.

Keywords: Dental Crown; Flexible Bronchoscopy; Removal; Alligator Forceps

\section{Introduction}

A foreign body in an airway is typically observed in children under 3 years old and in elderly people [1]. For respiratory physicians, they encounter a bronchial foreign body and generally observe the foreign bodies in elderly patients which often include all kinds of foods, dentures and dental crowns [2]. In older patients, the risk is higher due to the reduced gag reflex, and other agerelated general diseases such as dementia due to Parkinson's disease [3]. Once a foreign body is sometimes stuck in the trachea and bronchial space, and if it could not be discharged, it might cause asphyxia and pneumonia, thus an accurate diagnosis and prompt removal should be demanded. In recent years, for almost all cases of airway foreign bodies, the removal was performed by fiberoptic bronchoscopy. Based on the National Survey 2010 by the Japan Society for Respiratory Endoscopy [4], 681 cases of airway foreign body removal were reported and 662 (97\%) of which had been performed using a fiberoptic bronchoscopy. As a treatment of the foreign body in the airway, fiberoptic bronchoscopy was the first choice for its removal. However, it sometimes becomes a difficult removal of a very smooth surface of metallic dental prostheses.
There are a few reports regarding the effective extraction of dental prostheses from the airway [5-7]. The irregular surface and hard composition of dental prostheses make them very difficult to grasp and extract using normally effective instruments (biopsy forceps, Fogarty balloon catheters, alligator forceps, or wire baskets). Moreover, their sharp edges can facilitate impaction. For these reasons, we report the successful removal of a dental crown using a flexible bronchoscope, which was deeply inserted and nearly totally occluded the left lower peripheral bronchial tree.

\section{Case Report}

A 57-year-old male diagnosed with schizophrenia had been treated for tooth decay. During covering a dental crown, the palladium was dropped in the oral space. He had a continuous cough and was suspected of aspiration of the dental crown thus he was transferred to another hospital. Chest radiography showed a metallic foreign body in the left lower lung field (Figures 1A \& 1B) and he visited the emergency department of our hospital. Chest computed-tomography showed an artifact, that is, a foreign metal 
body in the left basal segmental bronchus of B9 of the lung (Figures 2A-2C). An endobronchial foreign body was diagnosed, and endoscopic removal was scheduled as the first steps before surgical removal. Under airway anesthesia, a flexible bronchoscopy was guided to the stuck dental crown in the B9 endobronchus (Figure
3A), which was grasped (Figure 3B) and successfully removed by alligator forceps. As the dental crown is made of palladium with a smooth surface, and firmly fixed the peripheral bronchus, it should be difficult to remove, however, we could strongly grasp it using alligator forceps for a digestive endoscope.

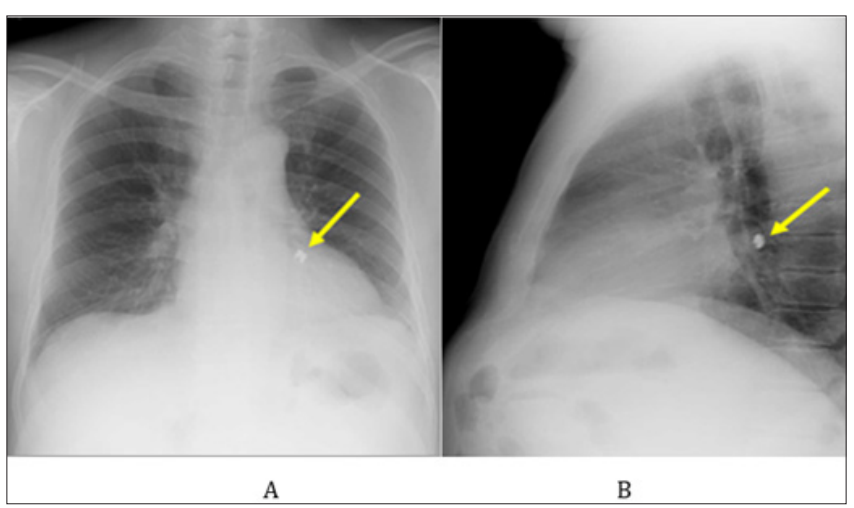

Figure 1: Chest radiographic film.

A. A small metal (the dropped dental crown) was located in the left lower airway (yellow arrow).

B. The foreign body was located in posterior and lower airway (yellow arrow).

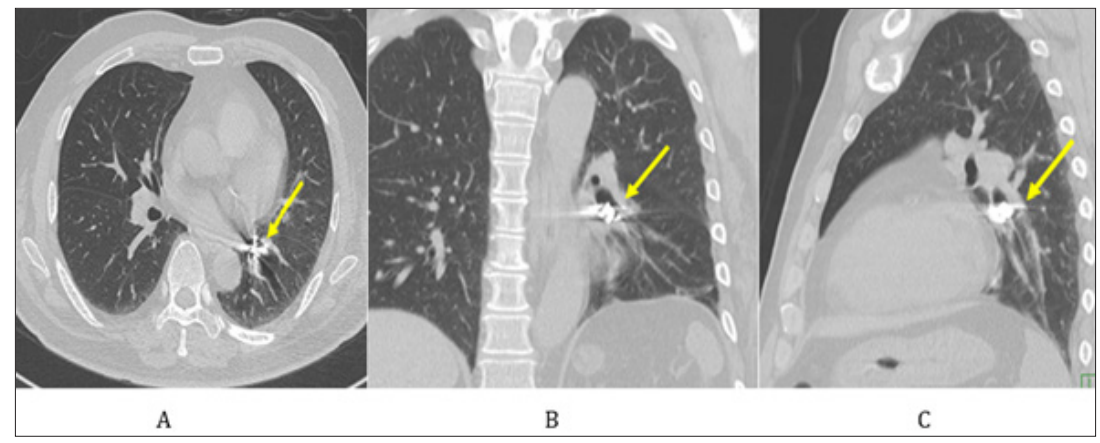

Figure 2: Chest computed-tomographic scanning.

A. Metal artifact was shown in lesion of the left lower lobe (yellow arrow).

B. Metal artifact was located in the left lower and basal bronchus (yellow arrow).

C. Metal artifact was shown in the orifice of the left lower and basal bronchus (yellow arrow).

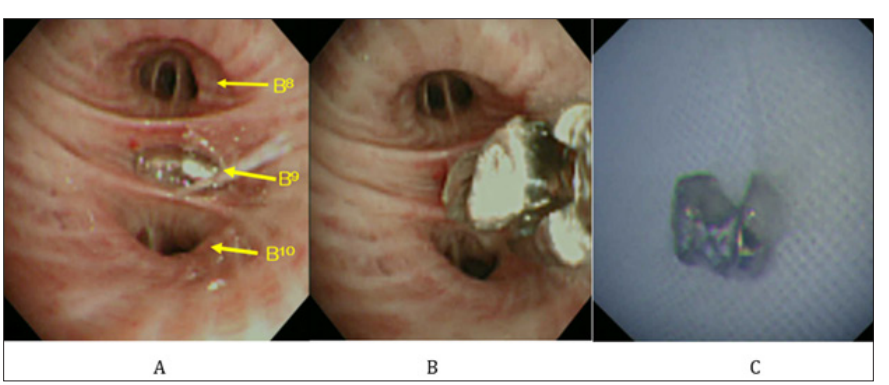

Figure 3 Bronchoscopic findings of the left lower basal bronchus.

A. The metal body was stuffed in the B9 bronchus.

B. The metal body was grasped by alligator forceps.

C. The removed metal body was found to be dental crown, that is palladium. 


\section{Discussion}

Foreign body aspiration is an uncommon clinical entity in adults $[8,9]$. A foreign body in the bronchial airway is commonly known to be found in infants and in elderly people, in contrast, few occur in middle age adults and seniors without basic diseases. Identification of a foreign body aspiration requires a high index of clinical suspicion, especially in those presenting without a history of aspiration. The radiological manifestations of foreign bodies or indirect signs (representing airway obstruction) occur in the form of nonresolving pneumonia, athelectasis, unilateral hyperinflation, or localized bronchiectasis, especially in those with organic foreign bodies $[1,10,11]$. This is explained by the anatomical features of the right main bronchus, which is wider in diameter, shorter in length, and has a more direct extension of the trachea than the left bronchus [7]. The most common location for a foreign body in the airway is the right bronchial tree, particularly, the right lowerlobe of the right main bronchus [8]. Further more, the left main bronchus does not branch at the same acute angle [7]. Two-thirds of aspirated objects lodge in the main bronchi rather than in the distal bronchi [3]. In this case, the foreign body was dropped in the left distal bronchi (Figures 1A \& 1B). Bilateral foreign bodies were present in only one subject and are rare. The foreign bodies could not be identified in $25 \%$ of the subjects possibly due to spontaneous expulsion of the foreign body, dissolution of an organic foreign body, or embedding of a small foreign body in the granulation tissue or edematous mucosa [1].

Regarding the diagnosis and treatment of foreign body aspiration is difficult to establish in adult subjects who present no a history of aspiration [8]. Most subjects with a history of foreign body aspiration present late to a medical facility (only $25 \%$ of subjects presented within 7 day of aspiration) [9]. Clinical suspicion of foreign body aspiration usually requires immediate admission to a hospital where the patient is initially studied by chest radiography to assess the presence of the foreign body or possible pleuroparenchymal and/or mediastinal changes [12]. Recent radiological literature has highlighted the diagnostic contribution of bronchoscopy [13], computed tomography (CT) [10], highresolution CT [14], spiral CT [15] and virtual bronchoscopy with multi-slice CT (MSCT) [16,17] in the evaluation of patients with suspected tracheobronchial aspiration of foreign bodies, leading to reconsideration of the role traditionally attributed to chest radiography [18]. Computed-tomographic scanning is a very useful method and there was no abnormal findings in $11 \%$ of the X-ray pictures [19]. CT is clearly more accurate than chest radiography in detecting radiolucent foreign bodies, and it should be performed in patients with a low level of clinical suspicion of foreign body aspiration in whom the chest radiography is negative [12]. In this case, computed-tomographic scanning could display the exact location of the foreign body (Figures 2A-2C).

In the case of aspiration during dental treatment, the patient had a clear subjective symptom and the occurrence time and the foreign body were obvious, thus the physician can easily handle it. Timely bronchoscopic removal of the aspirated airway foreign bodies is a must. In this case, the patient had been transferred to our hospital within several hours after the aspiration event of the dental crown. Delayed diagnosis can be associated with a number of complications. These include infective postobstructive complications such as pneumonia and lung abscess [20]. If recurrent infections are complicated by bronchiectasis, excessive granulation tissue formation will occur on the surface of the foreign bodies, which make it difficult to recognize and remove. The foreign body should be removed as soon as possible. On the other hand, in the case of an episode of unclear aspiration, for more than 10-years, a foreign body has been incarcerated, which was accidentally found by a detailed medical examination of pneumonia and atelectasis [21,22]. The longer the airway foreign body continued to incarcerate in the tracheobronchial space for a long time, the granulation formation significantly increased and made the situation easy to hemorrhage, and as a result, it then becomes difficult to remove by fiberoptic bronchoscopy. In the study of 200 cases [23], the frequency of granulation formation was reported to be $22.7 \%$ if the incarcerated period was short, i.e., within 3 days, was $62.5 \%$ if the incarcerated period was within 3 days to 1 week, and was $89.7 \%$ if the time was longer than one month. The longer the incarcerated time, the frequency of granulation formation increased. The status of incarceration with granulation and edema should result in the onset of asphyxia, athelectasis, pneumonia, and empyema $[24,25]$. Regarding the prognosis of airway foreign bodies, if the incarcerated period is greater than one month, the removal becomes difficult because of the increasing amount of granulation formation and edematous change [24,25].

The general trend in dentistry is to treat patients in a supine position to improve visibility, accessibility to the oral cavity as well as the ergonomic comfort for the operations [21]. Although the supine position seems more susceptible to accidental aspiration/ ingestion of foreign bodies [26], such mishaps may occur in any position at any time, not only during dental treatment, but also after treatment as the patients carry the appliances or prostheses in their mouth. In this case, the dental crown was dropped in the oral space when the tooth with palladium. A single-tooth cast or prefabricated restorations are more likely aspirated during their fitting and cementation. Tiwana et al. [27] in a 10-year institutional review of aspiration and ingestion in dental practice reported that among all dental specialties, fixed prosthodontic treatment had the highest incidence of adverse outcomes followed by orthodontic treatment. Foreign bodies in dental practice include the whole tooth, root tips and screwdriver, brackets, orthodontic sires, expansion keys and retainer, drills, amalgam fragments, temporary crown, pins and metallic posts, and impression materials [28]. The incidences of aspiration and ingestion during a dental procedure have been reported in many articles and reviews.

As early as 1971, Grossman [29] determined that $87 \%$ of foreign bodies entered the alimentary tract, whereas $13 \%$ aspirated into the respiratory tract. G Susini et al. [30] determined that the incidences of aspiration and ingestion during root canal treatment were 0.001 per 100,000 and 0.12 per 100,000 , respectively. From different dental college hospitals in Japan, the ingestion of foreign bodies was reported to be 0.0041 and $0.0044 \%$ [31,32]. The 
literature showed that although 9\% of ingested foreign bodies could uneventfully pass through the gastrointestinal tract, roughly $10 \%$ require endoscopic removal, while still $1 \%$ will even require an operation $[3,29,31,33]$. Although bronchoscopy has been reported to be $99 \%$ effective for retrieving the aspirated foreign bodies, the complication rate is between $2.4 \%$ and $5 \%$ [34]. The aspiration or injection of instruments or materials used in dentistry is a relatively common risk during many dental procedures [7]. Items that are more commonly accidentally inspired or swallowed include teeth, restorations and restrative materials, instruments, implant parts, rubber dam clamps, impression materials and crowns [28,35-37]. The aspiration and ingestion of foreign bodies are rare and risky complications during a dental procedure. Each accident should have thorough documentation so as to provide enough information for its treatment and prevention [38].

In the case that a dental crown had strongly been incarcerated in the peripheral endobronchus, and had made a severe granulation formation of the circumference of the airway foreign body in addition to the bronchial-self tension, the foreign body should not be removed by the usual fiberoptic bronchoscopic treatment. In this case, the dental crown was dropped in the oral space and aspirated during dental treatment. If the patient has a good general condition and good cooperation during the medical treatment, in almost all cases, the foreign body can be removed by fiberoptic bronchoscopy under local anesthesia. However, in the cases of complications of cerebrovascular disease, mental illness, drinking too much alcohol, drug abuse, the diagnosis of a foreign body in the airway becomes difficult, because of the long time from the aspiration of the airway by the foreign body, which makes it difficult to remove it. In many cases, a foreign body in the airway can be generally removed by fiberoptic bronchoscopy. Flexible bronchoscopy is more convenient as patients are only lightly sedated.

During flexible bronchoscopy, a foreign body can be directly visualized, or granulation tissue, endobronchial stenosis, or edema, all features of tissue reaction to an aspirated foreign body, may be present $[39,40]$. Flexible bronchoscopy is a safe and effective means of retrieving foreign bodies in the airway in the adult population. In a previous study [9] spanning $>3$ decades, only 1 in 400 bronchoscopies were performed for foreign body removal (similar to the proportion in the systemic review). The success rate of flexible bronchoscopy for the extraction of foreign bodies was $92 \%$ in the study [9] similar to that in the systemic review (89.3\%). However, in cases of a large foreign body in the airway and in addition to a long time having passed, even though in adults, it sometimes requires an airway intervention therapy by a rigid bronchoscopy. In the case of a complicated injury to the trachea and bronchial airway, it should need an open thoracotomy and removal by a surgical technique. Fortunately, in this case, the metallic palladium could be successfully removed by the flexible bronchoscopy.

The removal of a foreign body can be performed with a flexible bronchoscope or a rigid bronchoscope. The bronchoscopist in charge of the procedure must be skilled and familiar with the two modalities. The first attempt should be well planned, given that the number of unsuccessful attempts increases the risk of complications, such as swelling, bleeding, perforation, pneumothorax, and displacement into the central airways, which can be lethal [40]. After the foreign body removal, the tracheobronchial tree should be carefully examined; if symptoms or abnormal X-ray findings persist, a new endoscopic procedure should be scheduled [40]. Regarding the treatment of a foreign body in the airway, the first choice of the appropriate treatment was removal by fiberoptic bronchoscopy, and if it was impossible, as the next stage, a rigid bronchoscopic removal had better be used, however, even though the foreign body cannot be removed, finally, surgical removal is required [19]. Although a rigid bronchoscopy is considered the gold standard for the removal of foreign bodies from the airway [41,42], however, in a stable adult, the flexible bronchoscopy can be safe and effectively used in the diagnosis and treatment [40]. For the difficult cases regarding the removal of a foreign body in the airway by flexible bronchoscopy, sometimes the removal by rigid bronchoscopy and open thoracotomy were reported [23]. A rigid bronchoscope is used to remove foreign bodies in the airway on most occasions, because of the advantage of better airway control, direct visualization, and easier use of removal instruments [43].

The rigid bronchoscopy offers the advantage of direct visualization and the ability to simultaneously manage the airway. Furthermore, its larger internal diameter allows greater instrumentation options. On the other hand, the flexible bronchoscopy allows access to the smaller and more distal segments of the lung, particularly, the upper lobes. However, with a relatively limited working port, options for instrumentation through the flexible bronchoscope are fewer than with the rigid bronchoscopy. Extraction of dental prostheses has been particularly challenging because the metal component and irregular shape make grasping with traditional endoscopic equipment difficult. Therefore, a multidisciplinary team approach, using a rigid bronchoscope, flexible bronchoscopy, and fluoroscopy for retraction of airway dental crowns has been reported [6]. Many complications can occur after a foreign body extraction, including laryngeal/ pulmonary edema, hemoptysis, pneumothorax, tracheoesophageal fistula, pneumonia, atelectasis, fever, and respiratory failure [40]. Complications might require prolonged hospitalization, including intensive care, intubation, mechanical entilation and additional bronchoscopic procedures $[44,45]$. During the removal of a foreign body from the airway, it sometimes causes endobronchial bleeding.

Based on the Nationwide Survey 2010 by The Japan Society for Respiratory Endoscopy [4], regarding the complications of removal of a foreign body in the airway, 12 cases of bleeding $(1.76 \%)$ and 1 case of pneumothorax $(0.15 \%)$ were reported. A variety of instruments is used during flexible bronchoscopy to extract a foreign body, such as grasping forceps or Dormia basket, depending on the nature of the foreign body [9]. Grasping or tooth forceps (alligator, shark-tooth, and rat-tooth) should be used to remove a flat or thin inorganic or hard organic foreign body [8]. Shark-tooth and alligator forceps were used most often in the study because metallic or firm foreign bodies were the most common [9]. For the devise used in the endoscopic removal of the foreign body in the airway, 
there are many kinds of shaped forceps, which should be stocked such as each type of different shapes of basket forceps, alligator type, three claws type, $\mathrm{V}$ font type, $\mathrm{W}$ font type, and forceps with a rubber basket type, and collecting tools with magnets. However, generally, the forceps for fiberoptic bronchoscopy are thin and its waist is thin, compared to those of digestive endoscopy.

On the other hand, as those for digestive endoscopy were thick and the waist was thick, these instruments were useful for the removal of an endobronchial foreign body. As the handling of the endoscopic removal of a foreign body needs many forceps and instruments, these techniques result in taking a lot of time, thus bronchoscopic manipulation should be performed under intubation and sufficient anesthesia. In this case, we removed the metallic palladium dental crown by using the alligator forceps for the digestive endoscopy under local anesthesia while awake. In the study of 200 cases [23], 7 cases (3.5\%) of which could not be removed by fiberoptic bronchoscopy, the breakdown showed incarceration in the bronchus $(n=4)$, granulation formation $(n=2)$, bleeding $(n=1)$, which could not be removed by fiberoptic bronchoscopy, but were able to be removed by surgical treatment. The success rate of removal of airway foreign bodies by fiberoptic bronchoscopy was reported to be between 60 to $90 \%[1,39,46]$. Reshad et al. [47] reported the outcomes of 11 cases which could not be removed by fiberoptic bronchoscopy but could be removed by surgical operation, and 7 cases which occurred from several weeks to several years from the aspiration onset to the diagnosis, which combined with lung abscess, empyema, hemoptysis [48].

To avoid surgical treatment, it should be important to perform an early-term diagnosis and treatment as soon as possible. The use of bronchoscopy has dramatically reduced the need for a thoracotomy [7]. Bronchoscopy must be performed before any kind of mucosal inflammation, edema or fibrotic reaction sets in; this treatment is effective in more than $90 \%$ of the cases [49-52]. In a few cases, other solutions may be needed, that is, surgical removal under thoracoscopy or bronchoscopy and/or surgical resection [7]. In the rare instances in which the bronchoscopic removal fails, surgical bronchoscopy or segmental resection is indicated [40]. The presence of chronic bronchial obstruction, together with bronchiectasis, lung abscess, and parenchymal destruction, might be an indication for segmental or lobar resection [53].

\section{Conclusion}

In addition to the use of a basket catheter, under the X-ray perspective, the guide-wire for digestive endoscopy is also used. By applying both techniques and the instruments of digestive endoscopy, these removal skills can be increased. For the removal technique by fiberoptic bronchoscopy, we can use various types of instruments. As a minimally invasive therapy, a flexible bronchoscopy removal is safe and effective as the first choice of dental crown removal in order to avoid a maximally invasive surgical resection.

\section{References}

1. Limper AH, Prakash UB (1990) Tracheobronchial foreign bodies in adults. Ann Intern Med 112(8): 604-609.
2. Kaneko K, Akaishi T, Nakamura S (2005) Bronchial foreign bodies in adults. J Jpn Soc Resp Endoscopy 27: 518-523.

3. Fields RT, Schow SR (1998) Aspiration and ingestion of foreign bodies in oral and maxillofacial surgery: a review of the literature and report of five cases. J Oral Maxillofac Surg 56(9): 1091-1098.

4. Asano F, Aoe M, Ohsaki Y, Okada Y, Sasada S, et al. (2012) Death and complications associated with respiratory endoscopy: a survey by the Japan Society for Respiratory Endoscopy in 2010. Respirology 17: 478485.

5. Tu CY, Chen HJ, Chen W, Liu YH, Chen CH (2007) A feasible approach for extraction of dental prostheses from the airway by flexible bronchoscopy in concert with wire loop snares. Laryngoscope 117(7): 1280-1282.

6. Weber SM, Chesnutt MS, Barton R, Cohen JI (2005) Extraction of dental crowns from the airway: a multidisciplinary approach. Laryngoscope 115(4): 687-689.

7. Cossellu G, Farronato G, Carrassi A, Angiero F (2015) Accidental aspiration of foreign bodies in dental practice: clinical management and prevention. Gerodontology 32(3): 229-233.

8. Rafanan AL, Mehta AC (2001) Adult airway foreign body removal. What's new? Clin Chest Med 22(2): 319-330.

9. Sehgal IS, Dhooria S, Ram B, Singh N, Aggarwal AN, et al. (2015) Foreign Body Inhalation in the Adult Population: Experience of 25,998 Bronchoscopies and Systematic Review of the Literature. Respir Care 60(10): 1438-1448.

10.Zissin R, Shapiro Feinberg M, Rozenman J, Apter S, Smorjik J, et al. (2001) CT findings of the chest in adults with aspirated foreign bodies. Eur Radiol 11(4): 606-611.

11.Zitzmann N, Elsasser S, Fried R, Marinello CP (1999) Foreign body ingestion and aspiration. Oral Surg Oral Med Oral Pathol Oral Radiol Endod 88(6): 657-660.

12. Pinto A, Scaglione M, Pinto F, Guidi G, Pepe M, et al. (2006) Tracheobronchial aspiration of foreign bodies: current indications for emergency plain chest radiography. [Article in English, Italian] Radiol Med 111(4): 497-506.

13. Casson AG, Guy JR (1987) Foreign-body aspiration in adults. Can J Surg 30(3): 193-194.

14. Janoski MM, Raymond GS, Puttagunta L, Man GC, Barrie JR (2000) Psyllium aspiration causing bronchiolitis: radiographic, high-resolution CT, and pathologic findings. AJR Am J Roentgenol 174(3): 799-801.

15. Applegate KE, Dardinger JT, Lieber ML, Herts BR, Davros WJ, et al. (2001) Spiral CT scanning technique in the detection of aspiration of LEGO foreign bodies. Pediatr Radiol 31(12): 836-840.

16. Haliloglu M, Ciftci AO, Oto A, Gumus B, Tanyel FC, et al. (2003) CT virtual bronchoscopy in the evaluation of children with suspected foreign body aspiration. Eur J Radiol 48(2): 188-192.

17. Koşucu P, Ahmetoğlu A, Koramaz I, Orhan F, Ozdemir O, et al. (2004) Low-dose MDCT and virtual bronchoscopy in pediatric patients with foreign body aspiration. AJR Am J Roentgenol 183(6): 1771-1777.

18. Svedström E, Puhakka H, Kero P (1989) How accurate is chest radiography in the diagnosis of tracheobronchial foreign bodies in children? Pediatr Radiol 19(8): 520-522.

19. Baharloo F, Veyckemans F, Francis C, Biettlot MP, Rodenstein DO (1999) Tracheobronchial foreign bodies: presentation and management in children and adults. Chest 115(5): 1357-1362.

20. Jamshed N, Madan K, Ekka M, Guleria R (2014) Successful flexible bronchoscopic management of a large-sized aspirated partial denture. BMJ Case Rep. pii: bcr2013202371.

21. Nemoto K, Itoh M, Semba S, Junzou Ishida, Naohiro Shimizudani, Hideki Adachi, et al. (2010) A Case of chronic cough and recurrent pneumonia 
due to an intrabronchial foreign body (fish bone), undiagnosed for 20 years. J Jpn Soc Resp Endoscopy 32: 269-273.

22. Fujiwara A, Okumura N, Yamashina A (2015) An endobronchia foreign body overlooked for 37 years that was ultimately removed with a flexible bronchifiberscope. J Jpn Soc Resp Endoscopy 37: 163-167.

23. Dong YC, Zhou GW, Bai C, Huang HD, Sun QY, et al. (2012) Removal of tracheobronchial foreign bodies in adults using a flexible bronchoscope: experience with 200 cases in China. Intern Med 51: 2515-2519.

24. Todoroki F, Sato S, Ito M, Ikeda S, Okada Y (1970) [Case of lung cancer probably induced by an intrabronchial foreign body (fish bone)]. [Article in Japanese] Kyobu Geka 23(1): 55-58.

25. Takasa Akiyuki, Nakayama Masayuki, Bando Masashi, Nakasone Etsuko, Mizushima Yoshiko, et al. (2012) Clinical Characteristics of Aiway Foreign Bodies in Which Bronchoscopic Removal Difficult. J Jpn Soc Resp Endoscopy 34: 6-10.

26. Yadav RK, Yadav HK, Chandra A, Yadav S, Verma P, Shakya VK. (2015) Accidental aspiration/ingestion of foreign bodies in dentistry: A clinical and legal perspective. Natl J Maxillofac Surg 6(2): 144-151.

27. Cameron SM, Whitlock WL, Tabor MS (1996) Foreign body aspiration in dentistry: a review. J Am Dent Assoc 127(8): 1224-1229.

28. Tiwana KK, Morton T, Tiwana PS (2004) Aspiration and ingestion in dental practice: a 10-year institutional review. J Am Dent Assoc 135(9): 1287-1291

29. Grossman LI (1971) Prevention in endodontic practice. J Am Dent Assoc 82(2): 395-396.

30. Susini G, Pommel L, Camps J (2007) Accidental ingestion and aspiration of root canal instruments and other dental foreign bodies in a French population. Int Endod J 40(8): 585-589.

31. Hisanaga R, Hagita K, Nojima K, Katakura A, Morinaga K, et al. (2010) Survey of accidental ingestion and aspiration at Tokyo Dental College Chiba Hospital. Bull Tokyo Dent Coll 51(2): 95-101.

32. Obinata K, Satoh T, Towfik AM, Nakamura M (2011) An investigation of accidental ingestion during dental procedures. J Oral Sci 53(4): 495-500.

33. Abusamaan M, Giannobile WV, Jhawar P, Gunaratnam NT (2014) Swallowed and aspirated dental prostheses and instruments in clinical dental practice: a report of five cases and a proposed management algorithm. J Am Dent Assoc 145(5): 459-463.

34. Black RE, Johnson DG, Matlak ME (1994) Bronchoscopic removal of aspirated foreign bodies in children. J Pediatr Surg 29(5): 682-684.

35. Cameron SM, Whitlock WL, Tabor MS (1996) Foreign body aspiration in dentistry: a review. J Am Dent Assoc 127(8): 1224-1229.

36. Hodges ED, Durham TM, Stanley RT (1992) Management of aspiration and swallowing incidents: a review of the literature and report of case. ASDC J Dent Child 59(6): 413-419.

37. Pingarrón Martín L, Morán Soto MJ, Sánchez Burgos R, Burgueño García M (2010) Bronchial impaction of an implant screwdriver after accidental aspiration: report of a case and revision of the literature. Oral Maxillofac Surg 14(1): 43-47.
38. Hou R, Zhou H, Hu K, Ding Y, Yang X, et al. (2016) Thorough documentation of the accidental aspiration and ingestion of foreign objects during dental procedure is necessary: review and analysis of 617 cases. Head Face Med 12(1): 23.

39. Chen CH, Lai CL, Tsai TT, Lee YC, Perng RP (1997) Foreign body aspiration into the lower airway in Chinese adults. Chest 112(1): 129-133.

40. Rodrigues AJ, Oliveira EQ Scordamaglio PR, Gregório MG, Jacomelli M, et al. (2012) Flexible bronchoscopy as the first-choice method of removing foreign bodies from the airways of adults. [Article in English, Portuguese] J Bras Pneumol 38(3): 315-320.

41. Korlacki W, Korecka K, Dzielicki J (2011) Foreign body aspiration in children: diagnostic and therapeutic role of bronchoscopy. Pediatr Surg Int 27(8): 833-837.

42. Grover S, Bansal A, Singhi SC (2011) Airway foreign body aspiration. Indian J Pediatr 78(11): 1401-1403.

43. Linegar AG, Von Oppell UO, Hegemann S, De Groot M, Odell JA (1992) Tracheobronchial foreign bodies. Experience at Red Cross Children's Hospital, 1985-1990. S Afr Med J 82(3): 164-167.

44. Boyd M, Chatterjee A, Chiles C, Chin R (2009) Tracheobronchial foreign body aspiration in adults. South Med J 102(2): 171-174.

45. Li Y, Wu W, Yang X, Li J (2009) Treatment of 38 cases of foreign body aspiration in children causing life-threatening complications. Int J Pediatr Otorhinolaryngol 73(12): 1624-1629.

46. Lan RS (1994) Non-asphyxiating tracheobronchial foreign bodies in adults. Eur Respir J 7(3): 510-514.

47. Reshad K, Hitoimi S, Wada H, Kenji Inui, Hirohiko Ikushima, et al. (1994) The relation between complication rate and period between aspiration and the time of diagnosis in patient with bronchial foreign bodies. J Jpn Soc Resp Endoscopy 16: 437-444.

48. Massie J, Fink M (2010) Suspected foreign body inhalation in children: what are the indications for bronchoscopy? J Pediatr 156(4): 690-691.

49. Donado Uña JR1, De Miguel Poch E, Casado López ME, Alfaro Abreu JJ (1998) Fiber optic bronchoscopy in extraction of tracheo-bronchial foreign bodies in adults. [Article in Spanish] Arch Bronconeumol 34(2): 76-81.

50. Martinot A, Closset M, Marquette CH, Hue V, Deschildre A, et al. (1997) Indications for flexible versus rigid bronchoscopy in children with suspected foreign-body aspiration. Am J Respir Crit Care Med 155(5): 1676-1679.

51. Schumann C, Kropf C, Rüdiger S, Wibmer T, Stoiber KM, et al. (2010) Removal of an aspirated foreign body with a flexible cryoprobe. Respir Care. 55(8): 1097-1099.

52. Isherwood J, Firmin R (2011) Late presentation of foreign body aspiration requiring extracorporeal membrane oxygenation support for surgical management. Interact Cardiovasc Thorac Surg 12(4): 631-632.

53. Ogata Ryo, Takashima Junpei, Arizumi Toshihiro, Tanio Yoshiro (2010) A Bronchial Foreign Body (Dental Crown) Removed Using a Bronchoscope with Digestive Endoscopic Basket Catheter. J Jpn Soc Resp Endoscopy 32: 416-421. 


\section{ISSN: 2574-1241}

DOI: $10.26717 / B J S T R .2018 .11 .002167$

Takanori Ayabe. Biomed J Sci \& Tech Res

(C) (i) This work is licensed under Creative

Commons Attribution 4.0 License

Submission Link: https://biomedres.us/submit-manuscript.php

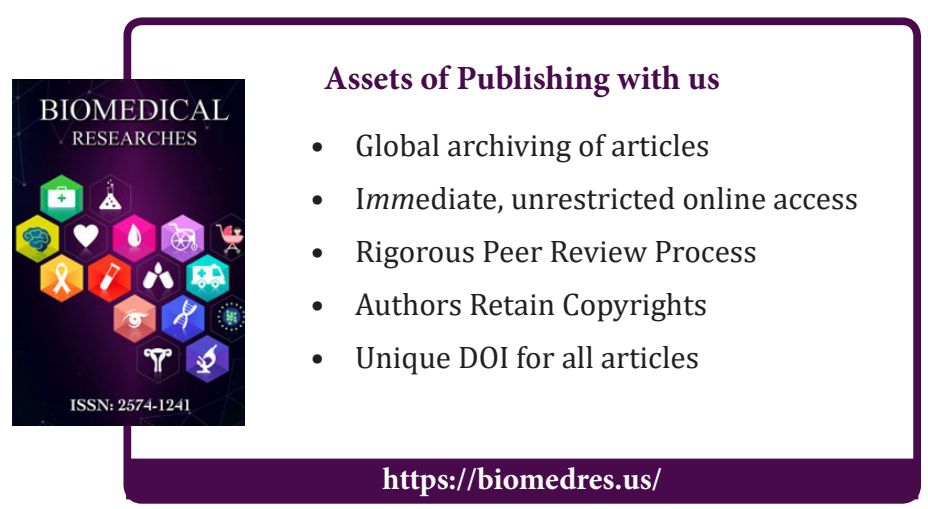

